\title{
STAT1 inhibits human hepatocellular carcinoma cell growth through induction of p53 and Fbxw7
}

\author{
Jiayu Chen ${ }^{1 \dagger}$, Haihe Wang ${ }^{2 \dagger}$, Jing Wang ${ }^{3}$, Shishun Huang ${ }^{2}$ and Wei Zhang ${ }^{4 *}$
}

\begin{abstract}
Background: Aberrant STAT1 signaling is observed in human hepatocellular carcinoma (HCC) and has been associated with the modulation of cell proliferation and survival. However, the role of STAT1 signaling in HCC and its underlying mechanism remain elusive.

Methods: We transiently transfected pCDNA3.1-STAT1 and STAT1 siRNA into SMMC7721 and HepG2 cells. Western blot and qRT-PCR examined the expression of protein and RNA of target genes. Cell viability was assessed using MTT assay, and cell cycle and apoptosis were analyzed by flow cytometry.

Results: We found that STAT1 overexpression increased protein expression of p53 and Fbxw7, and downregulated the expression of cyclin A, cyclin D1, cyclin E, CDK2, Hes-1 and NF-KB p65. These changes led to growth inhibition and induced G0/G1 cell cycle arrest and apoptosis in SMMC7721 and HepG2 cells. Conversely, ablation of STAT1 had the opposite effect on p53, Fbxw7, Hes-1, NF-KB p65, cyclin A, cyclin D1, cyclin E and CDK2, and improved the viability of SMMC7721 and HepG2 cells.

Conclusions: Our data indicate that STAT1 exerts tumor-suppressive effects in hepatocarcinogenesis through induction of G0/G1 cell cycle arrest and apoptosis, and may provide a basis for the design of new therapies for the intervention of HCC in the clinic.
\end{abstract}

Keywords: STAT1, HCC, Cell cycle arrest, Apoptosis, SMMC7721, HepG2

\section{Background}

Hepatocellular carcinoma (HCC) accounts for $80-90 \%$ of liver cancers and is the eighth most commonly occurring cancer in the world [1]. Epidemiological studies have revealed that cirrhosis with hepatitis virus infection is the most predominant risk factor for HCC development [2]. Emerging lines of evidence indicate that aberrant activation of several signaling cascades, including the activator of transcription (Jak/STAT), epidermal growth factor receptor (EGFR), Ras/extracellular signal-regulated kinase (ERK), CDKN1C/P57, phosphoinositol 3-kinase (PI3K)/mammalian target of rapamycin

\footnotetext{
*Correspondence: zhangyanjie3@aliyun.com

${ }^{\dagger}$ Jiayu Chen and Haihe Wang contributed equally to this work

${ }^{4}$ Department of Pathology, School of Medicine, Zhejiang University,

Hangzhou 310058, China

Full list of author information is available at the end of the article
}

(mTOR) [3], Cyclooxygenase-2/Snail/E-cadherin, NF-kB [4-7] and HGF/cMET pathways [8, 9] contributes to the pathogenesis of HCC. Our previous study has indicated that the mRNA and protein expression of STAT1 were significantly downregulated in the HCC tumor tissues compared to the normal tumor-adjacent tissues [10]. However, the mechanisms underlying the disruption of these critical pathways in the tumorigenesis of HCC are still not fully elucidated.

There is compelling evidence that STAT1 play an important role in promoting apoptotic cell death, and has been supported by the findings that growth inhibiting and pro-apoptotic activities of interferon-gamma (IFN- $\gamma$ ) are largely mediated by STAT1 signaling [11]. It has been observed that IFN-үinduce apoptotic sensitization of cells to various death signals such as TNF- $\alpha$, Fas, TRAIL $[12,13]$. Our previous study pointed out that STAT1 
may inhibit HCC growth by regulating the p53-related cell cycling and apoptosis in HepG2 cell [10]. Increasing evidence now suggests that STAT1 signaling also mediates non-apoptotic cell death, a category which includes necrotic and autophagic cell death. The mechanisms of non-apoptotic pathways, which often involves reactive oxygen species (ROS) and a caspase-independent pathway. In addition, STAT1 pathway may play an important role in antiviral defense, inflammation, and injury in liver disease [14]. STAT1 is crucial for the control of hepatitis $\mathrm{C}$ virus (HCV) replication although the HCV core protein can selectively degrade STAT1, and subsequently subvert the Jak-STAT kinase [15]. It is possible that STAT1 negatively regulate the growth of HCC. However, how STAT1 regulates the growth of HCC has not been clarified.

In this present study, we tested the impact of induction or knockdown of STAT1 expression on the proliferation, apoptosis and cell cycle of HCC cell line SMMC7721 and HepG2. We have demonstrated that STAT1 upregulation can significantly inhibit the in vitro growth of SMMC7721 and HepG2. Conversely, STAT1 knockdown promoted proliferation in the same cell line. STAT1induced growth suppression is at least partially due to apoptosis and G0/G1 cell cycle arrest. Consistent with cell cycle arrest, expression levels of cyclin A, cyclin D1, cyclin E, and CDK2 protein all decreased. Upregulation of p53 and Fbxw7 expression and downregulation of NF-kB p65 and Hes-1 were observed, and may be related to STAT1-induced apoptosis. Therefore, Our data suggest that STAT1 may be a negative regulator of the development and progression of human HCC growth through induction of apoptosis and cell cycle arrest.

\section{Results}

\section{STAT1 overexpression induces apoptosis and cell cycle} arrest in SMMC7721 and HepG2 cells

SMMC7721 and HepG2 cells were engineered to transiently express high levels of a recombinant plasmid encoding the STAT1 sequence (pcDNA3.1-STAT1) or control empty vector (EV) pcDNA3.1. The levels of STAT1 expression were determined by qRT-PCR and western blot assays. Compared with the control, the levels of STAT1 proteins in the pcDNA3.1-STAT1-transfected cells showed higher expression than that in the EV and unmanipulated cells (Fig. 1a). Similarly, the levels of STAT1 mRNA in the pcDNA3.1-STAT1-transfected cells were significantly higher than that in the EV and unmanipulated cells (Fig. 1b). The results of the MTT assay (Fig. 1c) indicate that overexpression of STAT1 caused growth inhibition in SMMC7721 and HepG2 cells. The pcDNA3.1-STAT1-transfected cells grew significantly more slowly than that in the EV and unmanipulated cells
$(\mathrm{P}<0.05)$. We monitored apoptosis in cultured cells by staining them with Annexin V and Propidium Iodide (PI) for subsequent flow cytometry analysis. We found that apoptosis was more prevalent in pcDNA3.1-STAT1transfected cells than in EV $(\mathrm{P}<0.05)$ (Fig. 1d, f). Furthermore, flow cytometry analysis was used to measure the cell cycle distribution, as predicted, pcDNA3.1STAT1-transfected SMMC7721 and HepG2 cells showed a higher proportion of cells in G0/G1 phase (88.17 and $90.87 \%$ ) compared with control EV cells (76.80 and $77.27 \%)(\mathrm{P}<0.05)$, indicating that STAT1 significantly inhibited cell cycle progression (Fig. 1e, g), suggesting that STAT1 induces G0/G1 cell cycle arrest and apoptosis in SMMC7721 and HepG2 cells.

\section{Knockdown of STAT1 expression activates proliferation of SMMC7721 and HepG2 cells}

SMMC7721 and HepG2 cells were used to monitor cell survival and growth based on cell cycle and apoptosis after transfection with STAT1 siRNA or control siRNA. To test siRNAs efficiency, STAT1 transcript levels were evaluated by western blot and qRT-PCR assays. We found that all of the tested siRNA effectively reduced the levels of STAT1 expression and transfection with the siRNA1, siRNA2, and siRNA3, resulted in inhibition of STAT1 expression by nearly 75,86 , and $65 \%$ (Fig. 2a, b, c). MTT assay revealed that the ablation of STAT1 improved SMMC7721 and HepG2 cells viability, the STAT1 knockdown cells growing significantly faster than control siRNA-transfected or untreated cells $(\mathrm{P}<0.05)$ (Fig. 2d). Flow cytometry analysis was used to analyze the cell cycle and rate of apoptosis. The result showed that STAT1 knockdown lowered the rate of apoptosis in SMMC7721 and HepG2 cells $(\mathrm{P}<0.05$, Fig. 2e, g) compared with control siRNA-transfected cells $(\mathrm{P}<0.05)$. STAT1 knockdown significantly increased the cell cycle progression. The percentage of G0/G1 phase in siRNA-transfected SMMC7721 and HepG2 STAT1 cells (72.61 and $76.38 \%$ ) was lower than that of control siRNA cells (80.65 and $84.31 \%$ ) (Fig. 2f, h).

\section{STAT1 alters the expression of apoptosis-related proteins in SMMC7721 and HepG2 cells}

We analyzed the expression of apoptosis-related proteins p53, Fbxw7, Hes-1, and NF-kB p65 via western blot and qRT-PCR. Western blot analysis showed that transient pcDNA3.1-STAT1 induced a significant increase in p53 and Fbxw7 expression in SMMC7721 and HepG2 cells ( $\mathrm{P}<0.05$, Fig. $3 \mathrm{a}, \mathrm{b}, \mathrm{c})$, while the expression of Hes-1 and NF-kB p65 were significantly decreased compared with SMMC7721, HepG2 and EV cells, $(\mathrm{P}<0.05$, Fig. 3a, $\mathrm{d}, \mathrm{e})$. We also monitored the mRNA expression of these proteins using qRT-PCR and obtained similar results (not shown). After transfection with STAT1 siRNA2 or 


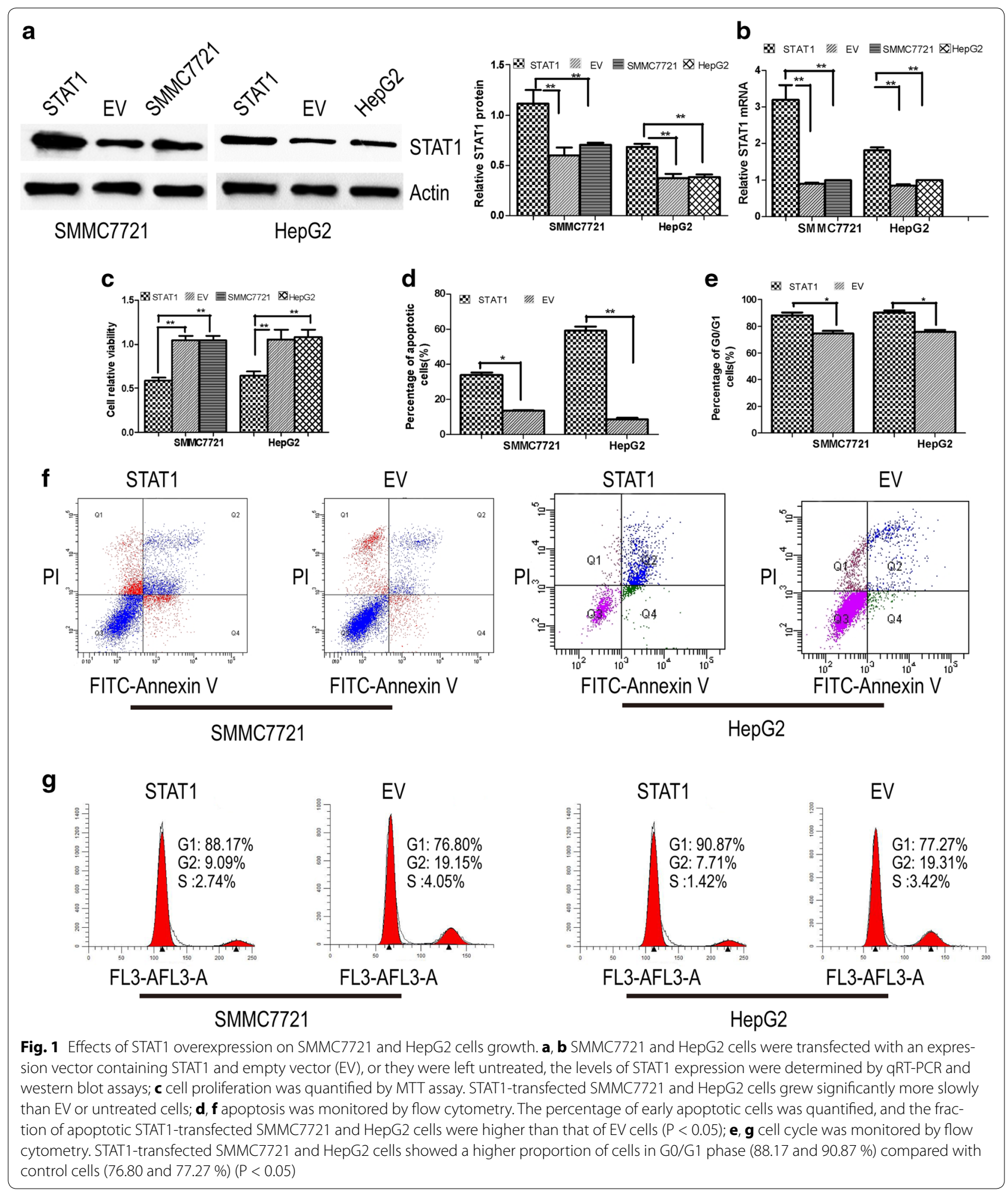

control siRNA, Hes-1 and NF-kB p65 expression were increased (Fig. 3f, i, j), whereas p53 and Fbxw7 were down-regulated in STAT1 siRNA2 cells compared with control siRNA-transfected cells $(\mathrm{P}<0.05)$ (Fig. 3f, g, h).
STAT1 down-regulates the expression of cyclin A, cyclin D1, cyclin E, CDK2 in SMMC7721 and HepG2 cells

Western blot analysis showed that $48 \mathrm{~h}$ after transient transfection with pcDNA3.1-STAT1, cyclin A, cyclin D1, 


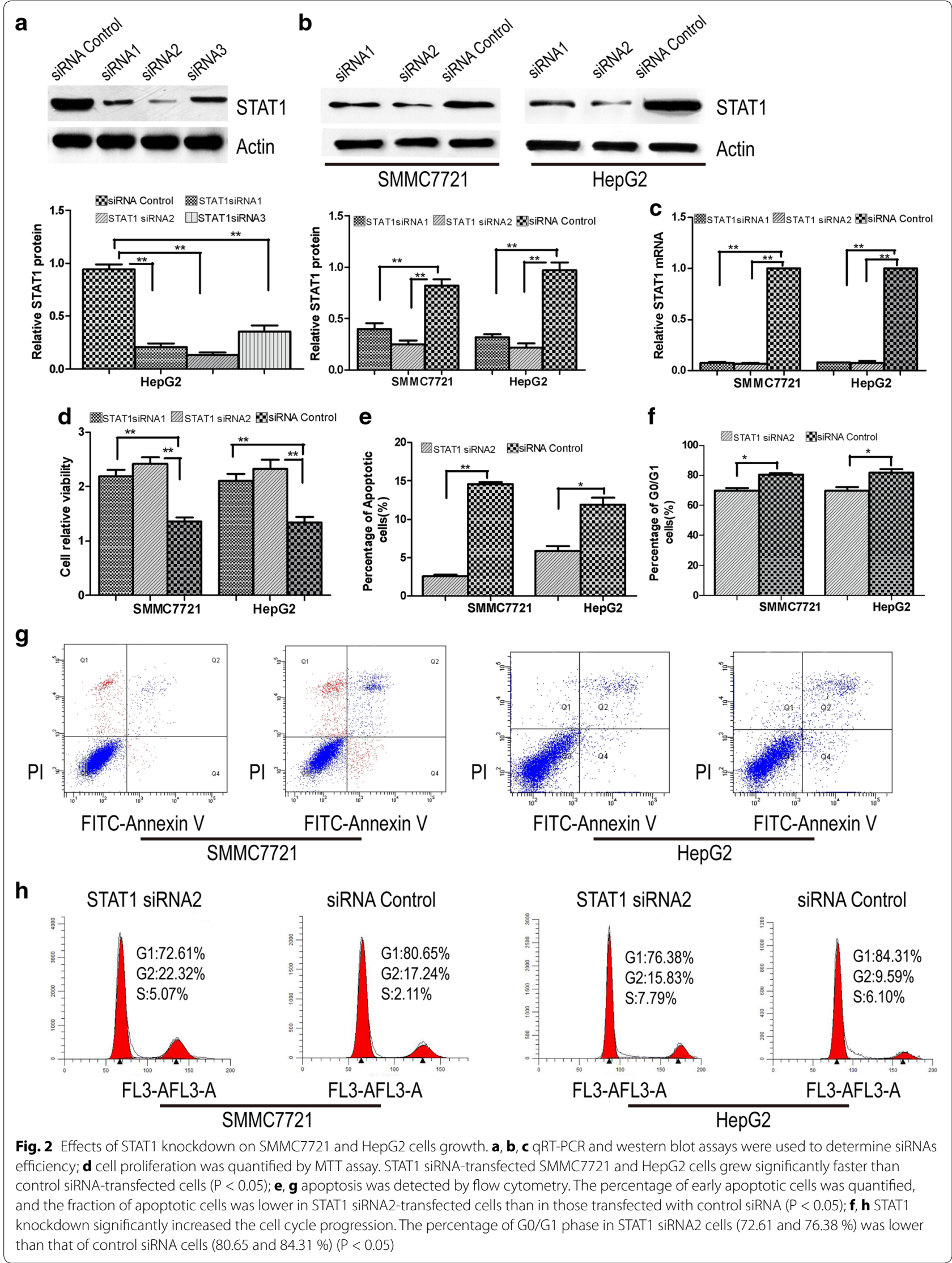




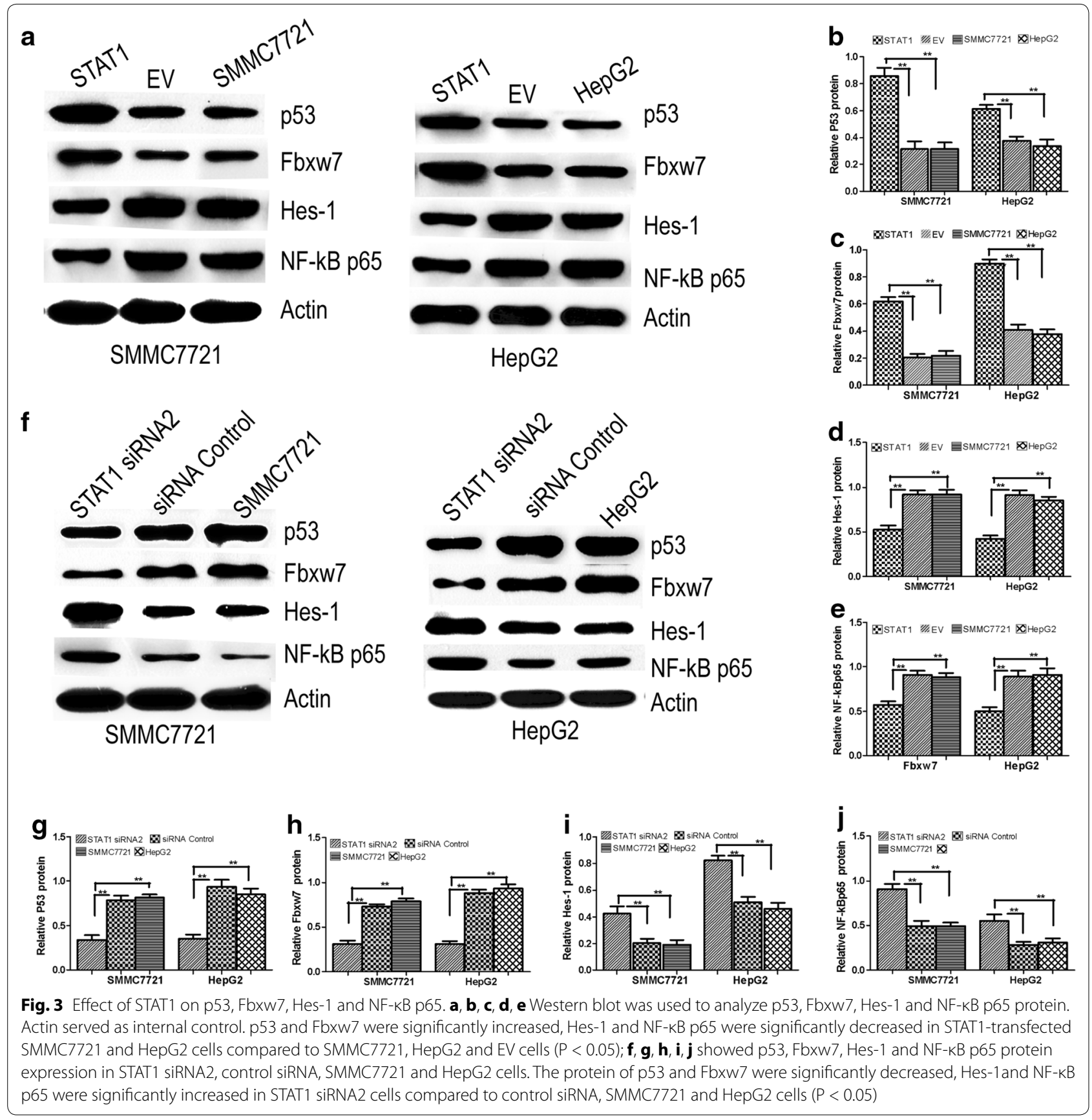

cyclin E and CDK2 expression levels were significantly decreased ( $\mathrm{P}<0.05$, Fig. 4a, b, c, d, e), when compared with SMMC7721, HepG2 and EV cells. In contrast, cyclin A, cyclin D1, cyclin E and CDK2 expression levels were significantly increased $48 \mathrm{~h}$ after transient transfection with STAT1 siRNA2 when compared with control siRNA-transfected cells $(P<0.05$, Fig. 4f, g, h, i, j). The mRNA expression of these proteins were consistent with those obtained by western blot (not shown).

\section{Discussion}

The signal transducers and activators of transcription (STATs) belong to a family of seven cytoplasmic proteins that function as signal messengers and transcription factors participating in cellular responses to cytokines and growth factors [16, 17]. Among these proteins, the STAT1 plays a critical role in the regulation of diverse biological actions, including antiviral defense, induction of cell death, and growth arrest [18]. 


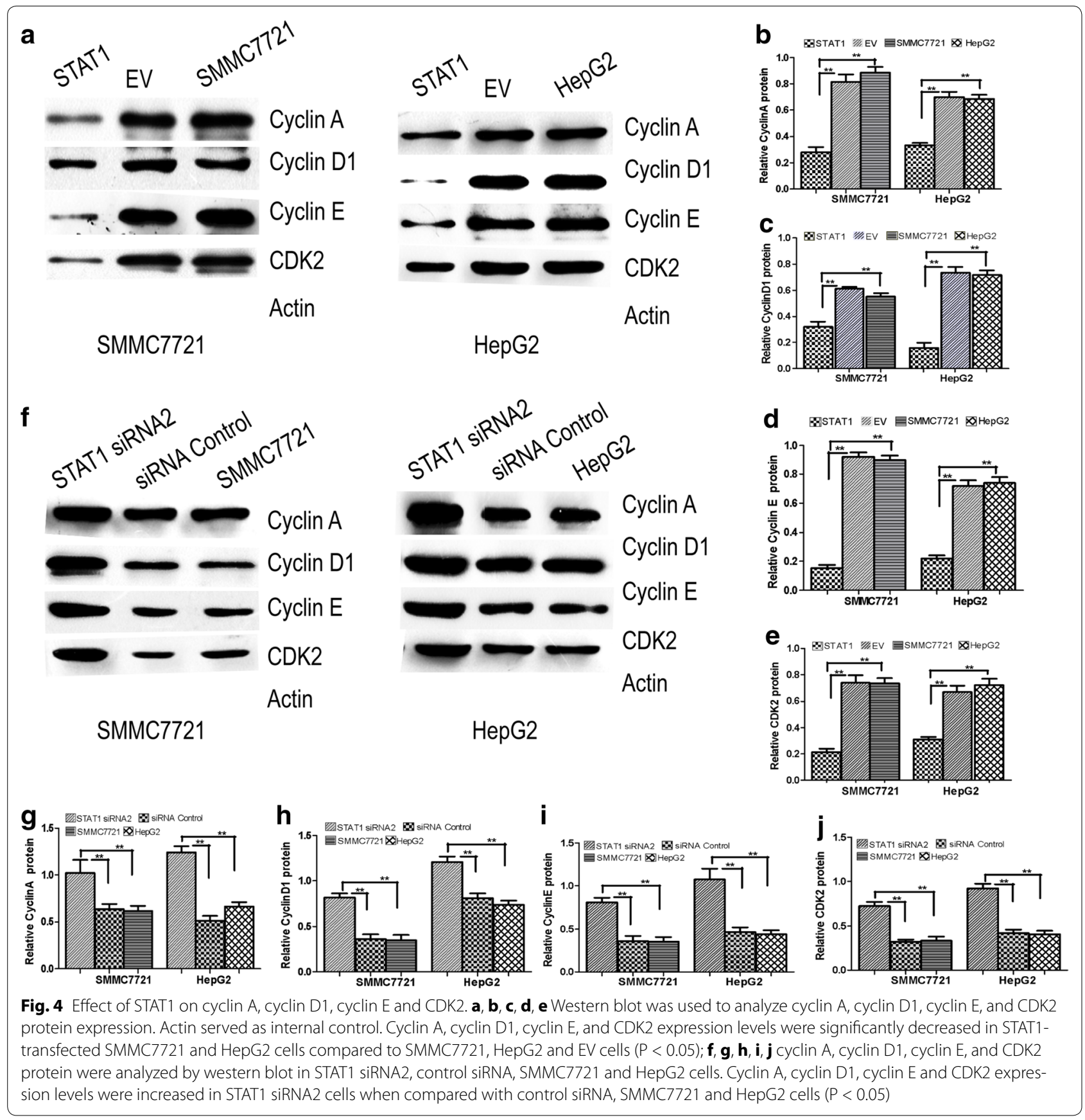

In this study, we transiently transfected STAT1 expression vectors and STAT1-specific siRNA into SMMC7721 and HepG2 cells to investigate the function of STAT1 in driving HCC development or progression. We observed that STAT1 overexpression caused growth inhibition, induced G0/G1 cell cycle arrest and promoted apoptosis in SMMC7721 and HepG2 cells, whereas ablation of STAT1 improved viability. The role of the STAT1 cascade in tumor is controversial, and despite strong data indicating that STAT1 downregulation was most prominent in the tumor cells themselves when compared with the surrounding stroma and infiltrating lymphocytes $[19,20]$. Studies demonstrated that STAT1 controls antitumorigenic effects in part by upregulation of caspases $1,2,3,7$, and 8 [21], cyclin-dependent kinase inhibitor 1A (CDKN1A) [22], IFN-regulatory Factor 1 (IRF1)/p53 pathway [23], and down-regulation of B cell CLL/Lymphoma 2 (BCL2) family [24]. In contrast, other groups 
have found that in certain cellular contexts the STAT1 pathway may mediate tumor cell growth. Overexpression of the IFN/STAT1 pathway is associated with poor prognosis in different types of cancer, and selected against fractionated ionizing radiation (IR) and IFN-resistant phenotype from a radiosensitive parental tumor SCC61 [25-27].

Apoptosis and cell cycle arrest involve complex molecular cascades, and dysfunction of various genes may lead to the onset and progression of apoptosis and cell cycle arrest. We explored the mechanism of STAT1-induced apoptosis and cell cycle arrest by assessing the effect of STAT1 on the expression of apoptosis-related factors (p53, Fbxw7, Hes-1, and NF-кB p65) and cell cycle regulators (cyclin A, cyclin D1, cyclin E, and CDK2) in SMMC7721 and HepG2 cells. It is well recognized that STAT1 promotes cell death through mechanisms that are dependent upon transcriptional activation of genes encoding proteins involved in modulating or promoting cell death, such as caspases, death receptors and ligands, iNOS, and Bcl-xL, as well as those involved in cell cycle arrest, such as p21 WAF1. It is also interesting to note that STAT1 can associate with proteins that are directly or indirectly involved in apoptotic cell death, including TRADD, p53, HATs and HDAC. Previous studies have demonstrated that overexpression of mutant or wildtype p53 can result in apoptotic cell death and that p53 can cause cell cycle arrest by transcriptionally upregulating p21 [28]. Fbxw7 is a key tumor suppressor that regulates cell proliferation in different HCC cell lines. It has been shown that Fbxw7 is directly regulated by p53 [29]. High levels of Fbxw7 might decrease the pool of available cell cycle regulators (cyclin A, cyclin E), triggering arrest in G1 phase and accounting for low proliferation rates. NF- $\mathrm{kB}$ signaling has been recognized as the major pathway responsible for cytokine-associated cancer development, inactivation of NF- $\mathrm{kB}$ inhibits cell growth and induces intrinsic apoptosis in hepatocellular carcinoma cells [30]. Protein levels and kinase activities of cyclin A, cyclin D1, cyclin E and CDK4 are significantly elevated in $\mathrm{HCC}$, and decreased levels of cyclin D1 have been correlated with growth inhibition and G0-G1 cell cycle arrest [31, 32]. Here, we found a similar effect with STAT1 modulation in HCC cell lines. Our results showed that upon transient expression of active STAT1 in SMMC7721 and HepG2 cells, p53 and Fbxw7 expression levels were increased, whereas cyclin A, cyclin D1, cyclin E, CDK2, Hes-1 and NF- $\mathrm{kB}$ p65 were downregulated. STAT1 knockdown by siRNA caused downregulation of p53 and Fbxw7, and upregulation of cyclin A, cyclin D1, cyclin E, CDK2, Hes-1 and NF-KB p65. Taken together, our results suggest that STAT1 possibly induces G0-G1 cell cycle arrest through a mechanism of downregulating cyclin A, cyclin D1, cyclin E, CDK2, and Fbxw7 synergizing with p53 to trigger apoptosis in vitro. To the best of our knowledge, our study provides the first evidence for STAT1-induced G0/G1 cell cycle arrest and apoptosis in SMMC7721 and HepG2 cells.

\section{Conclusions}

In summary, our data indicated that STAT1 may function as a suppressor of $\mathrm{HCC}$ cell proliferation, and a regulator of HCC cell apoptosis and cell cycle arrest. Hence, our findings may provide a basis for the design of new therapies for the intervention of HCC in the clinic.

\section{Methods}

\section{Cell culture and transfections}

SMMC7721 and HepG2 cells were cultured in Dulbecco's modified Eagle's medium (DMEM) supplemented with $10 \%$ fetal calf serum at $37^{\circ} \mathrm{C}$ and $5 \% \mathrm{CO}_{2}$. The plasmids of pcDNA3.1 (EV) and pcDNA3.1-STAT1 were obtained from GenePharma. pcDNA3.1 (EV) and pcDNA3.1STAT1 were transfected into SMMC7721 and HepG2 cells at $70 \%$ confluence using X-tremeGENE HP DNA transfection reagent (Roche, Mannheim, Germany) according to the manufacturer's protocol. Cells were transfected for $48 \mathrm{~h}$ in 6-well plates and then analyzed for flow cytometry, MTT assay, western blot and qRT-PCR.

\section{RNA interference (RNAi)}

The sense and antisense sequences of the STAT1-specifc and control siRNAs were synthesized by GenePharma, Shanghai, China and are present in Table 1. SMMC7721 and HepG2 cells $\left(2 \times 10^{5} /\right.$ well $)$ were cultured in 6-well plates at $70 \%$ confluence, and transfected in duplicate with $1.3 \mu \mathrm{g}$ each type of STAT1-specific or control siRNA using X-tremeGENE siRNA transfection reagent (Roche, Mannheim, Germany) according to the manufacturer's instructions. Cells were transfected for $48 \mathrm{~h}$ in 6-well plates and then analyzed for flow cytometry, MTT assay, western blot and qRT-PCR.

\section{Cell cycle determination}

After transfection with the corresponding STAT1 vectors or siRNAs for $48 \mathrm{~h}$, the cells were harvested and washed twice with cold PBS, then fixed in $75 \%$ alcohol for $2 \mathrm{~h}$ at $4{ }^{\circ} \mathrm{C}$. After washing in cold PBS three times, cells were resuspended in $1 \mathrm{~mL}$ of PBS solution with $40 \mu \mathrm{g}$ of propidium iodide (Sigma) and $100 \mu \mathrm{g}$ of RNase A (Sigma) for $30 \mathrm{~min}$ at $37^{\circ} \mathrm{C}$ and analyzed with the BD Accuri C6 system (Becton-Dickinson, USA). The distribution of cells in different phases of the cell cycle was calculated using the Modifit LT software. 
Table 1 Primer for PCR amplification and siRNAs sequences

\begin{tabular}{ll}
\hline Sequencing primers & $\mathbf{5}^{\prime}$-3' $^{\prime}$ \\
\hline p53-F primer & CAGATCCCTTAGTTTTGGGTGC \\
p53-R primer & GCCTGGAGAGACCTAGACCA \\
Fbxw7-F primer & AAAGAGTTGTTAGCGGTTCTCG \\
Fbxw7-R primer & CCACATGGATACCATCAAACTG \\
HES-1-F primer & CCAAAGACAGCATCTGAGCA \\
HES-1-R primer & TCAGCTGGCTCAGACTTCA \\
NF-KB p65-F primer & TCTGCAACTGAAACGCAAGC \\
NF-KB p65-R primer & CTCCACAGCTTCTCTTACCTT \\
CDK2-F primer & CGGATCTTTCGGACTCTGGG \\
CDK2-R primer & GAGAGGGTGAGCCGATTAGG \\
CyclinA-F primer & CAGAGGCCGAAGACGAGAC \\
CyclinA-R primer & TCAGCTGGCTTCTTCTGAGC \\
CyclinD1-F primer & CTGGCCATGAACTACCTGGA \\
CyclinD1-R primer & GTCACACTTGATCACTCTCC \\
CyclinE-F primer & GTTATAAGGGAGACGGGGAG \\
CyclinE-R primer & TGCTCTGCTTCTTACCGCTC \\
RITA-F primer & GGGTGGAGAAGGCTAACAGAA \\
RITA-R primer & CATCACAGTAAGACGGGGTGT \\
GAPDH-F primer & AGGTGAAGGTCGAGTCAAC \\
GAPDH-R primer & CGCTCCTGGAAGATGGTGAT \\
siRNA1:STAT1_homo-575 sense & GCUGGAUGAUCAAUAUAGUTT \\
siRNA1:STAT1_homo-575 antisense & ACUAUAUUGAUCAUCCAGCTT \\
siRNA2:STAT1_homo-647 sense & GCGUAAUCUUCAGGAUAAUTT \\
siRNA2:STAT1_homo-647 antisense & AUUAUCCUGAAGAUUACGCTT \\
siRNA3:STAT1_homo-1601 sense & GCACCUGCAAUUGAAAGAATT \\
siRNA3:STAT1_homo-1601 antisense & UUCUUUCAAUUGCAGGUGCTT \\
Control-siRNA-sense & UUCUCCGAACGUGUCACGUTT \\
Control-siRNA-antisense & ACGUGACACGUUCGGAGAATT \\
\hline & \\
\hline
\end{tabular}

\section{Apoptosis analysis}

After transfection for $48 \mathrm{~h}$, the cells were harvested and washed three times with cold PBS. Cells were then resuspended in the staining buffer and stained using the Annexin V-FITC Apoptosis Assay Kit (Bestbio, Shanghai, China) according to the manufacturer's instructions. The stained cells were analyzed by flow cytometry (BD FACSAria, R\&D, USA). Annexin V-positive and propidium iodide-negative cells were counted as apoptotic cells.

\section{MTT assay}

Cell viability was assessed using the MTT colorimetric assay (R\&D, USA). SMMC7721 and HepG2 cells were seeded in 96-well plates at a density of $1 \times 10^{4}$ cells per well in $100 \mu \mathrm{L}$ complete medium. After transfection with the corresponding plasmid vector or siRNA, $10 \mu \mathrm{L}$ MTT solution $(5 \mathrm{mg} / \mathrm{mL})$ was added, and cells were incubated for an additional $4 \mathrm{~h}$. Subsequently, $100 \mu \mathrm{L}$ of MTT solubilization buffer was added to the wells. Following a 10-min mixing period, the absorbance was analyzed at $570 \mathrm{~nm}$ using a microplate reader. The background absorbance at $690 \mathrm{~nm}$ was subtracted from the $570 \mathrm{~nm}$ measurement. Each experiment was performed in triplicate, and the mean value was calculated.

\section{Quantitative Real-time reverse transcription-polymerase chain reaction (qRT-PCR)}

Total RNA was isolated from cultured cells using Trizol (Invitrogen, Carlsbad, California, USA) according to the manufacturer's instructions. RNA concentration and purity were determined from absorbance measured at both 260 and $280 \mathrm{~nm}$. RNA $(1 \mu \mathrm{g})$ was reverse transcribed using the PrimeScript ${ }^{\circledR}$ First Strand cDNA Synthesis Kit (Takara, Dalian, China) and random oligodeoxynucleotide primers. PCR amplification was performed in $20 \mu \mathrm{L}$ reactions containing cDNA generated from $2 \mathrm{ng}$ of the original RNA template, $400 \mathrm{nmol} / \mathrm{L}$ of each gene-specific forward and reverse primer, $10 \mu \mathrm{L}$ of $2 \times$ SYBR $^{\circledR}$ Premix Ex Taq ${ }^{\mathrm{TM}}$ II (Takara, Dalian, China), $0.4 \mu \mathrm{L}$ of ROX reference dye, and $6.0 \mu \mathrm{L}$ of $\mathrm{dH}_{2} \mathrm{O}$. Amplified signals were detected using the ABI PRISM 7300 Real-Time PCR system (ABI, USA). The annealing temperature was optimized using the temperature gradient program that is part of the ABI PRISM software. Experiments were performed in duplicate. The relative target mRNA levels were determined using the $2^{\Delta \Delta \mathrm{Ct}}$ method. The primer sequences used are summarized in Table 1.

\section{Western blot analysis}

Protein concentrations were determined using the $\mathrm{BCA}$ Protein Assay (Pierce, USA) according to the manufacturer's instructions. Samples containing equal amounts of protein $(40 \mu \mathrm{g})$ were resolved by $10 \%$ SDS-PAGE and transferred to nitrocellulose membranes. After blocking for $2 \mathrm{~h}$ at room temperature with TBS-T (0.1 M Tris, $0.9 \% \mathrm{NaCl}$, and $0.05 \%$ Tween-20 at $\mathrm{pH}$ 7.5) containing $5 \%$ skim milk, and probed at $4{ }^{\circ} \mathrm{C}$ overnight with rabbit anti-STAT1 (1:2000, Bioworld Technology), rabbit antip53 (1:400), rabbit anti-Fbxw7 (1:400), rabbit anti-cyclin A (1:400), rabbit anti-cyclin D1 (1:400), rabbit anti-cyclin E (1:400), rabbit anti-CDK2 (1:400) (Beijing Biosynthesis Biotechnology Co, Beijing, China), rabbit anti-NF- $\mathrm{kB}$ p65 (1:2000), rabbit anti-Hes-1 (1:2000) (Cell Signaling Technology Inc., Boston, USA), and mouse anti-actin (1:8000). Proteins were detected by exposing the blots to $\mathrm{X}$-ray film (Kodak).

\section{Statistical analysis}

SPSS version 17.0 software was used for all statistical analyses. All of the results are expressed as the mean \pm SD. Statistical analysis was performed using standard two-way ANOVA for repeated measurements, 
and the $\mathrm{X}^{2}$ test was used to analyze the flow cytometry data. $P$ values less than 0.05 were considered statistically significant.

\section{Authors' contributions}

JC has made substantial contributions to design, and has been involved in drafting and revising the manuscript. WZ have given final approval of the version to be published. HW has made substantial contributions to design, study and the analysis of data. JW has participated in analysis of data. SH has been involved in vitro study. All authors read and approved the final manuscript.

\section{Author details}

${ }^{1}$ Department of Laboratory Medicine, School of Medicine, Taizhou University, Taizhou 318000, Zhejiang, China. ${ }^{2}$ Department of Pathogenobiology, Daqing Branch of Harbin Medical University, Daqing 163319, China. ${ }^{3}$ Department of Endocrinology of Fifth Hospital of Daqing, Daqing 163714, China. ${ }^{4}$ Department of Pathology, School of Medicine, Zhejiang University, Hangzhou 310058, China.

\section{Acknowledgements}

This work was supported by Daqing Branch of Harbin Medical University

\section{Competing interests}

The authors declare that they have no competing interests.

Received: 25 August 2015 Accepted: 7 October 2015

Published online: 26 November 2015

\section{References}

1. Kang YH, Park MY, Yoon DY, Han SR, Lee Cl, Ji NY, Myung PK, Lee HG, Kim JW, Yeom Yl, Jang YJ, Ahn DK, Kim JW, Song EY. Dysregulation of overexpressed IL-32a in hepatocellular carcinoma suppresses cell growth and induces apoptosis through inactivation of NF-KB and Bcl-2. Cancer Lett. 2012:318:226-33.

2. Tu K, Zheng X, Zhou Z, Li C, Zhang J, Gao J, Yao Y, Liu Q. Recombinant human adenovirus-p53 injection induced apoptosis in hepatocellular carcinoma cell lines mediated by p53-Fbxw7 pathway, which controls c-Myc and cyclin E. PLoS One. 2013;8:e68574.

3. Giovannini C, Gramantieri L, Minguzzi M, Fornari F, Chieco P, Grazi GL, Bolondi L. CDKN1C/P57 is regulated by the Notch target gene Hes 1 and induces senescence in human hepatocellular carcinoma. Am J Pathol. 2012;181:413-22.

4. Saxena NK, Sharma D, Ding X, Lin S, Marra F, Merlin D, Anania FA Concomitant activation of the JAK/STAT, PI3K/AKT, and ERK signaling is involved in leptin-mediated promotion of invasion and migration of hepatocellular carcinoma cells. Cancer Res. 2007;67:2497-507.

5. Zhou L, Wang DS, Li QJ, Sun W, Zhang Y, Dou KF. The down-regulation of Notch 1 inhibits the invasion and migration of hepatocellular carcinoma cells by inactivating the cyclooxygenase- 2/Snail/E-cadherin pathway in vitro. Dig Dis Sci. 2013;58:1016-25

6. Wu K, Ding J, Chen C, Sun W, Ning BF, Wen W, Huang L, Han T, Yang W, Wang C, Li Z, Wu MC, Feng GS, Xie WF, Wang HY. Hepatic transforming growth factor beta gives rise to tumor-initiating cells and promotes liver cancer development. Hepatology. 2012;56:2255-67.

7. Villanueva A, Alsinet C, Yanger K, Hoshida Y, Zong Y, Toffanin S, RodriguezCarunchio L, Solé M, Thung S, Stanger BZ, Llovet JM. Notch signaling is activated in human hepatocellular carcinoma and induces tumor formation in mice. Gastroenterology. 2012;143:1660-9.

8. Nalesnik MA, Michalopoulos GK. Growth factor pathways in development and progression of hepatocellular carcinoma. Front Biosci (Schol Ed). 2012:4:1487-515.

9. Ho C, Wang C, Mattu S, Destefanis G, Ladu S, Delogu S, Armbruster J, Fan L, Lee SA, Jiang L, Dombrowski F, Evert M, Chen X, Calvisi DF. AKT (v-aktmurine thymoma viral oncogene homolog 1) and N-Ras (neuroblastoma ras viral oncogene homolog) coactivation in the mouse liver promotes rapid carcinogenesis by way of mTOR (mammalian target of rapamycin complex 1), FOXM1 (forkhead box M1)/SKP2, and c-Myc pathways. Hepatology. 2012;55:833-45.

10. Chen G, Wang H, Xie S, Ma J, Wang G. STAT1 negatively regulates hepatocellular carcinoma cell proliferation. Oncol Rep. 2013;29:2303-10.

11. Ossina NK, Cannas A, Powers VC, Fitzpatrick PA, Knight JD, Gilbert JR, Shekhtman EM, Tomei LD, Umansky SR, Kiefer MC. Interferon-gamma modulates a p53-independent apoptotic pathway and apoptosis-related gene expression. J Biol Chem. 1997;272:16351-7.

12. Suk K, Kim S, Kim YH, Kim KA, Chang I, Yagita H, Shong M, Lee MS. IFNgamma/TNF-alpha synergism as the final effector in autoimmune diabetes: a key role for STAT1/IFN regulatory factor-1 pathway in pancreatic beta cell death. J Immunol. 2001;166:4481-9.

13. Shin EC, Ahn JM, Kim CH, Choi Y, Ahn YS, Kim H, Kim SJ, Park JH. IFNgamma induces cell death in human hepatoma cells through a TRAIL/ death receptor-mediated apoptotic pathway. Int J Cancer. 2001;93:262-8.

14. Kim WH, Hong F, Radaeva S, Jaruga B, Fan S, Gao B. STAT1 plays an essential role in LPS/D-galactosamine-induced liver apoptosis and injury. Am J Physiol Gastrointest Liver Physiol. 2003;285:G761-8.

15. Lin W, Choe WH, Hiasa Y, Kamegaya Y, Blackard JT, Schmidt EV, Chung RT. Hepatitis $C$ virus expression suppresses interferon signaling by degrading STAT1. Gastroenterology. 2005; 128:1034-41.

16. Stark GR, Darnell JE Jr. The JAK-STAT pathway at twenty. Immunity. 2012;36:503-14

17. Vainchenker W, Constantinescu SN. JAK/STAT signaling in hematological malignancies. Oncogene. 2013;32:2601-13.

18. Balasubramanian A, Ganju RK, Groopman JE. Signal transducer and activator of transcription factor 1 mediates apoptosis induced by hepatitis $C$ virus and HIV envelope proteins in hepatocytes. J Infect Dis. 2006;194:670-81.

19. Chan SR, Vermi W, Luo J, Lucini L, Rickert C, Fowler AM, Lonardi S, Arthur C, Young LJ, Levy DE, Welch MJ, Cardiff RD, Schreiber RD. STAT1-deficient mice spontaneously develop estrogen receptor a-positive luminal mammary carcinomas. Breast Cancer Res. 2012;14:R16.

20. Schneckenleithner C, Bago-Horvath Z, Dolznig H, Neugebauer N, Kollmann K, Kolbe T, Decker T, Kerjaschki D, Wagner KU, Müller M, Stoiber D, SexI V. Putting the brakes on mammary tumorigenesis: loss of STAT1 predisposes to intraepithelial neoplasias. Oncotarget. 2011;2:1043-54.

21. Sironi JJ, Ouchi T. STAT1-induced apoptosis is mediated by caspases 2, 3, and 7. J Biol Chem. 2004;279:4066-74.

22. Chin YE, Kitagawa M, Su WC, You ZH, Iwamoto Y, Fu XY. Cell growth arrest and induction of cyclin-dependent kinase inhibitor p21 WAF1/CIP1 mediated by STAT1. Science. 1996;272:719-22.

23. Townsend PA, Scarabelli TM, Davidson SM, Knight RA, Latchman DS, Stephanou A. STAT-1 interacts with p53 to enhance DNA damageinduced apoptosis. J Biol Chem. 2004;279:5811-20.

24. Stephanou A, Brar BK, Knight RA, Latchman DS. Opposing actions of STAT- 1 and STAT-3 on the BCl-2 and BCl-x promoters. Cell Death Differ. 2000;7:329-30.

25. Khodarev NN, Beckett M, Labay E, Darga T, Roizman B, Weichselbaum RR. STAT1 is overexpressed in tumors selected for radioresistance and confers protection from radiation in transduced sensitive cells. Proc Natl Acad Sci USA. 2004;101:1714-9.

26. Khodarev NN, Roach P, Pitroda SP, Golden DW, Bhayani M, Shao MY, Darga TE, Beveridge MG, Sood RF, Sutton HG, Beckett MA, Mauceri HJ, Posner MC, Weichselbaum RR. STAT1 pathway mediates amplification of metastatic potential and resistance to therapy. PLoS One. 2009;4:e5821.

27. Khodarev NN, Minn AJ, Efimova EV, Darga TE, Labay E, Beckett M, Mauceri HJ, Roizman B, Weichselbaum RR. Signal transducer and activator of transcription 1 regulates both cytotoxic and prosurvival functions in tumor cells. Cancer Res. 2007:67:9214-20.

28. Roh JL, Kang SK, Minn I, Califano JA, Sidransky D, Koch WM. p53-Reactivating small molecules induce apoptosis and enhance chemotherapeutic cytotoxicity in head and neck squamous cell carcinoma. Oral Oncol. 2011:47:8-15

29. Tu K, Zheng X, Zan X, Han S, Yao Y, Liu Q. Evaluation of Fbxw7 expression and its correlation with the expression of c-Myc, cyclin E and p53 in human hepatocellular carcinoma. Hepatol Res. 2012;42:904-10.

30. Baud V, Karin M. Is NF-kappaB a good target for cancer therapy? Hopes and pitfalls. Nat Rev Drug Discov. 2009;8:33-40. 
31. Masaki T, Shiratori Y, Rengifo W, Igarashi K, Yamagata M, Kurokohchi K, Uchida N, Miyauchi Y, Yoshiji H, Watanabe S, Omata M, Kuriyama S. Cyclins and cyclin-dependent kinases: comparative study of hepatocellular carcinoma versus cirrhosis. Hepatology. 2003;37:534-43.
32. Suzui M, Masuda M, Lim JT, Albanese C, Pestell RG, Weinstein IB. Growth inhibition of human hepatoma cells by acyclic retinoid is associated with induction of p21(CIP1) and inhibition of expression of cyclin D1. Cancer Res. 2002;62:3997-4006.

Submit your next manuscript to BioMed Central and take full advantage of:

- Convenient online submission

- Thorough peer review

- No space constraints or color figure charges

- Immediate publication on acceptance

- Inclusion in PubMed, CAS, Scopus and Google Scholar

- Research which is freely available for redistribution

Submit your manuscript at

www.biomedcentral.com/submit

() BioMed Central 